\title{
Assessment of Association between Health and Nutritional Status of Geriatric Population in the Rural Area of Western Maharashtra, India
}

\author{
Badrinarayan Mishra', Rohit Avinash Vadgaonkar ${ }^{2}$ \\ ${ }^{1}$ Professor, Dept. of Community Medicine, Ruxmaniben Deepchand Gardi Medical College, Ujjain, Madhya Pradesh, India. \\ ${ }^{2}$ Ex. Intern, Rural Medical College, PIMS, Maharashtra, India.
}

DOI: https://doi.org/10.24321/2394.6539.202005

\section{I $\quad \mathbf{N} \quad \mathbf{F} \quad \mathbf{O}$}

\section{Corresponding Author:}

Badrinarayan Mishra, Dept. of Community Medicine, Ruxmaniben Deepchand Gardi Medical College, Ujjain, Madhya Pradesh, India.

E-mail Id:

badrinmishra@gmail.com

Orcid Id:

https://orcid.org/0000-0001-6956-0469

How to cite this article:

Mishra B, Vadgaonkar RA. Assessment of Association between Health and Nutritional Status of Geriatric Population in the Rural Area of Western Maharashtra, India. J Adv Res Med Sci Tech 2020; 7(2): 4-9.

Date of Submission: 2020-05-21

Date of Acceptance: 2020-06-29

\section{$\begin{array}{llllllll}\mathbf{A} & \mathbf{B} & \mathbf{S} & \mathbf{T} & \mathbf{R} & \mathbf{A} & \mathbf{C} & \mathbf{T}\end{array}$}

Background: Many chronic diseases are considered age-related. The study reports the existing health conditions of the geriatric population from rural Maharashtra.

Aims and Objectives: This cross-sectional study assessed the health conditions of the geriatric population in a rural area of Western Maharashtra and associated them with their sociodemographic and nutritional parameters.

Methodology: 260 participants were assessed by Gerald Jogrest 'Geriatric Health Questionnaire' and pertinent health issues were collected from the primary health centre and individual health records. Nutritional assessment was done by MNA (Mini Nutritional Assessment) questionnaire. SPSS version 20 software was used for data analysis.

Result: Out of 260, there were 148 (56.9\%) male and 112 (43.1\%) female participants and the mean age was 72.11 ( \pm 6.59$)$. All forms of functional living status were significant associations $(p<0.001)$ with nutritional status. Anaemia was found in $64.16 \%$. Cataract, joint pain, chronic cough, tuberculosis, and varicose veins were prevalent in females, whereas toothache, impaired hearing, hypertension, skin diseases, diabetes, and bladder issues were dominant ones among males. BMI (Body Mass Index) was significantly associated with joint complaints, chronic cough, bowel and bladder problems, and diabetes $(p<0.05)$.

Conclusion: The rural geriatric population faces the issue of a double dilemma. On one hand, there exists a significant nutritional vulnerability that impairs daily living, on the other hand, the association of BMI with select disease conditions highlights the emerging issue of obesity.

Keywords: Rural Geriatrics, Nutrition, Health Issues, ADL and IADL

\section{Introduction}

Ageing is a universal process. While some consider it as an incurable disease, others opine that "You do not heal old age, you protect it, you promote it and you extend it. ${ }^{1}$ India 
has made steady progress in the health care sector. From the time of independence to date we have improved our life expectancy from 32 to 69.73 years. ${ }^{2}$ This encouraging achievement has brought along new challenges; the challenge to bring up a fit and healthy senior citizens. For this purpose, it is important that accurate information is available about their health conditions and nutritional status.

\section{Aim}

The concluded study was designed to assess health status among the geriatric population in a rural area of western Maharashtra and associate them with their existing nutritional status.

\section{Objectives}

- To estimate the health condition of the geriatric population in a rural area and find the common comorbidities affecting them

- To estimate any association of morbidity pattern and grade of nutrition among the participants.

- To suggest recommendations to improve the picture

\section{Methodology}

A cross-sectional community-based study involving 260 participants over the age of 65 years was carried out to estimate the point prevalence of different study parameters. The select rural community comes under the field practice area of a rural medical college situated in western Maharashtra with an expected number of elderly at 197 i.e, $8.6 \%$ of the village that had a total population of 2472 with 1289 males and 1183 females, as per Census 2011. ${ }^{3}$

The sample size was calculated by the formula $4 \mathrm{pq} / \mathrm{I}^{2}$, where; $p$, the prevalence of malnutrition in the elderly was taken at $20 \%$, $q$ was $100-p=80$ and $\mathrm{l}$, the maximum allowable error was considered at $5 \%$. This yielded a sample of 256 which was rounded up to the closest figure of 260.

\section{Inclusion Criteria}

Participants were permanent residents of the village, aged $\geq 65$ years, with the ability to understand and answer the questions and willing to give written consent were enrolled for the study.

\section{Exclusion Criteria}

Participants with knowen malignancy and other severe illnesses were kept out.

EIC and ICMR Ethical approval were obtained by ICMR Reference Number: 2010-00995.

\section{Data Collection}

260 Individuals were selected by simple random technique from an available study population of 298 over a period of 3 months. The age of the participants was estimated preferably from the government-issued "Ration card." In case of its unavailability, the mean value of responses relating to the recalled age at marriage, age at vital events in the family was considered. ${ }^{4,5}$

The health status was assessed by the Geriatric Health Questionnaire: developed by Gerald Jogrest, the University of lowa, consisting of 9 different questions regarding general health, Activities of Daily Living, Instrumental Activities of Daily Living, Medications, Sexual activity, Immunization, etc. ${ }^{6}$

Morbidity profile was collected from available patient records relating to tuberculosis, diabetes, hypertension, other cardiac illness and other past illnesses. In the case of nonavailability of records, information was collected by on spot clinical examination by the investigator and assigned interns. Participants were examined for Hypertension by measuring blood pressure at participants home on 3 different times of the day on three different days of the week by WHO recommended standardized standing mercury sphygmomanometer with ISI certification. Eye diseases were screened for the presence of cataract by torchlight examination and presence of lens opacity and different eys shadows were recorded, vision test was carried out by Snellen chart, surgical illnesses, Respiratory diseases, and other Medical illness that includes joint problems, toothache, impaired hearing, skin problems, bowel, and bladder problems were detected by history and relevant clinical examinations like spirometry, webers tests, woods light, oral mirror and torch, etc. In addition to this information relating to general sociodemography was also gathered. Nutritional status was evaluated by MNA. ${ }^{7}$

\section{Data Analysis}

Data was coded and descriptive, and inferential analysis carried out by SPSS version 20. 'Chi-Square' test of significance' with Yates correction' was used at relevant places. 'Z-test' of variation between two means was applied to compare various anthropometric measurements with various grades of nutrition. ' $P$ ' value of significance was set at $<0.05$.

\section{Result}

There were 148 (56.9\%) males and 112 (43.1\%) females with the mean age of participants at $72.11( \pm 6)$.59 years. General sociodemographic characteristics of the studied population described in Table 1.

Functional status assessment (ADL and IADL) were compared with different grades of nutrition. It was observed that there was a significant association between functional status with that of a grade of nutrition $(p<0.001)$. The results are depicted in Table 2. 
Table I.Sociodemographic characteristics of participants

\begin{tabular}{|c|c|c|c|}
\hline \multicolumn{4}{|c|}{ Age distribution } \\
\hline Age (years) & Male & Female & Total \\
\hline $65-70$ & $76(51.35 \%)$ & $48(42.1 \%)$ & $124(47.69 \%)$ \\
\hline $71-75$ & $39(26.35 \%)$ & $34(30.36 \%)$ & $73(28.08 \%)$ \\
\hline $76-80$ & $13(8.78 \%)$ & $20(17.86 \%)$ & 33 (12.69\%) \\
\hline $81-90$ & $17(11.48 \%)$ & $7(6.25 \%)$ & $24(9.23 \%)$ \\
\hline$>90$ & $3(2.03 \%)$ & $3(2.68 \%)$ & $6(2.3 \%)$ \\
\hline Total & $148(100 \%)$ & $112(100 \%)$ & $260(100 \%)$ \\
\hline \multicolumn{4}{|c|}{ Economic status } \\
\hline Per capita income (Rs.)\# & Male & Female & Total \\
\hline$<350$ & $2(13 \%)$ & $3(2.6 \%)$ & $5(1.9 \%)$ \\
\hline $350-700$ & $24(16.2 \%)$ & $26(23.2 \%)$ & $50(19.2 \%)$ \\
\hline $700-1100$ & $48(32.4 \%)$ & $40(35.7 \%)$ & $88(33.8 \%)$ \\
\hline $1100-2200$ & $46(31 \%)$ & $28(25 \%)$ & $74(28.4 \%)$ \\
\hline$>2200$ & 28 (18.9\%) & $15(13.3 \%)$ & 43 (16.5\%) \\
\hline Total & $148(100 \%)$ & $112(100 \%)$ & $260(100 \%)$ \\
\hline \multicolumn{4}{|c|}{ \#As per modified B.G.Prasad classification. } \\
\hline \multicolumn{4}{|c|}{ Educational status } \\
\hline Education & Male & Female & Total \\
\hline Illiterate & $95(64.1 \%)$ & $88(78.5 \%)$ & $183(70.3 \%)$ \\
\hline primary & $26(17.5 \%)$ & $13(11.6 \%)$ & $39(15.2 \%)$ \\
\hline secondary and higher secondary & $18(12.1 \%)$ & $10(8.9 \%)$ & $28(10.7 \%)$ \\
\hline $10^{\text {th }}+$ & $9(6 \%)$ & $1(0.8 \%)$ & $10(3.8 \%)$ \\
\hline Total & $148(100 \%)$ & $112(100 \%)$ & $260(100 \%)$ \\
\hline \multicolumn{4}{|c|}{ Family support } \\
\hline Living with & Male & Female & Total \\
\hline Child and spouse & $85(57.4 \%)$ & $58(51.7 \%)$ & $143(55 \%)$ \\
\hline Child only & $28(18.9 \%)$ & $24(21.4 \%)$ & $52(20 \%)$ \\
\hline Spouse only & $22(14.8 \%)$ & 17 (15.1\%) & $39(15 \%)$ \\
\hline Others & 13 (8.78\%) & 13 (11.6\%) & $26(10 \%)$ \\
\hline Total & 148 (100\%) & 112 (100\%) & 260 (100\%) \\
\hline
\end{tabular}

Table 2.Association between Functional Status of daily leaving and grade of nutrition

\begin{tabular}{|c|c|c|c|c|c|}
\hline ADL/ IADL & Response & $\begin{array}{c}\text { Well- } \\
\text { nourished }\end{array}$ & $\begin{array}{l}\text { At the risk of } \\
\text { malnutrition }\end{array}$ & Undernourished & $\begin{array}{c}\text { Test of } \\
\text { significance }\end{array}$ \\
\hline \multirow{3}{*}{ Walking } & 1 & $96(84.96)$ & $88(79.28)$ & $13(36.11)$ & \multirow{3}{*}{$p<0.001$} \\
\hline & $A$ & $17(15.04)$ & 19 (17.12) & 15 (41.67) & \\
\hline & $\mathrm{D}$ & $0(0)$ & $4(3.6)$ & $8(22.22)$ & \\
\hline \multirow{3}{*}{ Eating } & 1 & $106(93.8)$ & 94 (84.69) & $16(44.44)$ & \multirow{3}{*}{$p<0.001$} \\
\hline & $A$ & $5(4.43)$ & 13 (11.71) & $13(36.11)$ & \\
\hline & $\mathrm{D}$ & $2(1.77)$ & $4(3.6)$ & 7 (19.44) & \\
\hline
\end{tabular}


Mishra B et al.

\begin{tabular}{|c|c|c|c|c|c|}
\hline \multirow{3}{*}{ Dressing } & 1 & 105 (92.92) & 89 (80.18) & $19(52.78)$ & \multirow{3}{*}{$p<0.001$} \\
\hline & A & $8(7.08)$ & 15 (13.51) & $11(30.56)$ & \\
\hline & $\mathrm{D}$ & $0(0)$ & $7(6.31)$ & $6(16.67)$ & \\
\hline \multirow{3}{*}{ Toileting } & 1 & 109 (96.46) & 94 (84.69) & $17(47.22)$ & \multirow{3}{*}{$p<0.001$} \\
\hline & $\mathrm{A}$ & $3(2.65)$ & 13 (11.71) & $14(38.89)$ & \\
\hline & $\mathrm{D}$ & $1(0.89)$ & $4(3.6)$ & $5(13.89)$ & \\
\hline \multirow{3}{*}{ Bathing } & 1 & 108 (95.57) & $89(80.18)$ & $21(58.33)$ & \multirow{3}{*}{$p<0.001$} \\
\hline & A & $5(4.43)$ & $15(13.51)$ & $9(25)$ & \\
\hline & $D$ & $0(0)$ & $7(6.31)$ & $6(16.67)$ & \\
\hline \multirow{3}{*}{ House-work } & 1 & $97(85.84)$ & 75 (67.57) & $12(33.33)$ & \multirow{3}{*}{$p<0.001$} \\
\hline & $\mathrm{A}$ & 15 (13.27) & $22(19.82)$ & $11(30.56)$ & \\
\hline & $\mathrm{D}$ & $1(0.89)$ & $14(12.61)$ & $13(36.11)$ & \\
\hline \multirow{3}{*}{ Shopping } & 1 & $97(85.84)$ & $82(73.87)$ & 15 (41.67) & \multirow{3}{*}{$p<0.001$} \\
\hline & $\mathrm{A}$ & $14(12.39)$ & $15(13.51)$ & $7(19.44)$ & \\
\hline & $\mathrm{D}$ & $2(1.77)$ & $14(12.61)$ & $14(38.89)$ & \\
\hline \multirow{3}{*}{$\begin{array}{c}\text { Taking } \\
\text { medications }\end{array}$} & 1 & 106 (93.8) & 83 (74.79) & $9(25)$ & \multirow{3}{*}{$p<0.001$} \\
\hline & A & $5(4.43)$ & $20(18.01)$ & $17(47.22)$ & \\
\hline & $\mathrm{D}$ & $2(1.77)$ & $8(7.2)$ & $10(27.78)$ & \\
\hline \multirow{3}{*}{$\begin{array}{l}\text { Managing } \\
\text { finances }\end{array}$} & 1 & $102(90.27)$ & 86 (77.48) & $9(25)$ & \multirow{3}{*}{$p<0.001$} \\
\hline & $\mathrm{A}$ & $7(6.19)$ & $15(13.52)$ & $16(44.44)$ & \\
\hline & D & $4(3.57)$ & $10(9)$ & $11(30.55)$ & \\
\hline
\end{tabular}

I- Independent; A- Requires assistance; D- Dependency. Values in bracket indicate percentage.

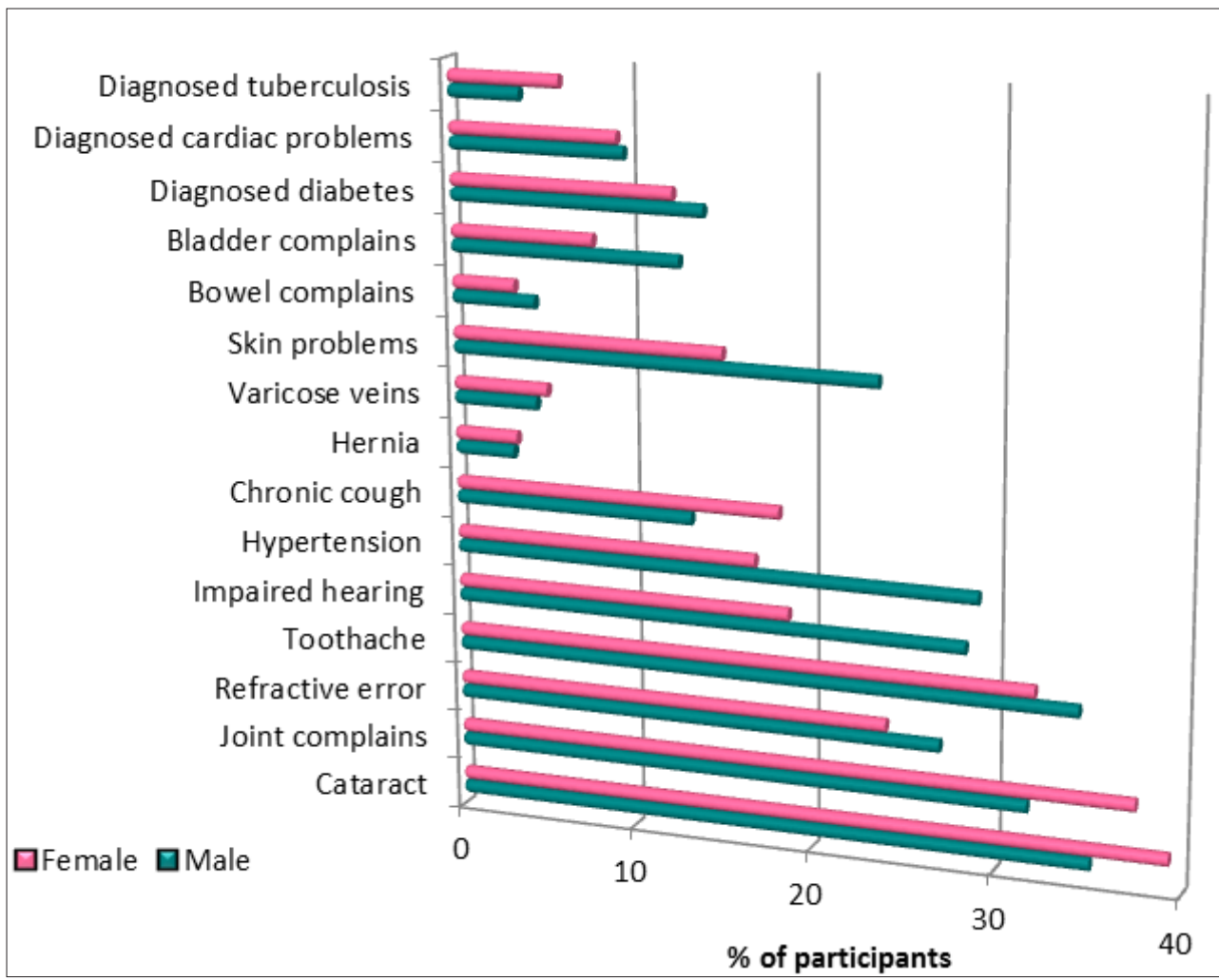

Figure I.Morbidities pattern reported in study participants 
Table 3.Association of morbid conditions with Body Mass Index in participants

\begin{tabular}{|c|c|c|c|c|}
\hline Morbidity & $\mathbf{> 2 3} \mathbf{~ k g} / \mathbf{m}^{\mathbf{2}}$ & $\mathbf{3 2 3} \mathbf{k g} / \mathbf{m}^{\mathbf{2}}$ & Total & Test of significance (p-value) \\
\hline Cataract & $41(42.71 \%)$ & $55(57.29 \%)$ & $96(100 \%)$ & $\mathrm{p}>0.05$ \\
\hline Joint complains & $47(52.81 \%)$ & $42(47.19 \%)$ & $89(100 \%)$ & $\mathrm{p}<0.05$ \\
\hline Refractive error & $35(52.24 \%)$ & $32(47.76 \%)$ & $67(100 \%)$ & $\mathrm{p}>0.05$ \\
\hline Toothache & $42(48.28 \%)$ & $45(51.72 \%)$ & $87(100 \%)$ & $\mathrm{p}>0.05$ \\
\hline Impaired hearing & $26(41.27 \%)$ & $37(58.73 \%)$ & $63(100 \%)$ & $\mathrm{p}>0.05$ \\
\hline Hypertension & $26(41.94 \%)$ & $36(58.06 \%)$ & $62(100 \%)$ & $\mathrm{p}<0.001$ \\
\hline Chronic cough & $9(21.42 \%)$ & $33(78.57 \%)$ & $42(100 \%)$ & $\mathrm{p}>0.05$ \\
\hline Hernia & $4(44.44 \%)$ & $5(55.56 \%)$ & $9(100 \%)$ & $\mathrm{p}>0.05$ \\
\hline Varicose veins & $6(46.15 \%)$ & $7(53.84 \%)$ & $13(100 \%)$ & $\mathrm{p}>0.05$ \\
\hline Skin problems & $22(42.31 \%)$ & $30(57.69 \%)$ & $52(100 \%)$ & $\mathrm{p}<0.05$ \\
\hline Bowel complains & $1(9.1 \%)$ & $10(90.9 \%)$ & $11(100 \%)$ & $\mathrm{p}<0.001$ \\
\hline Bladder complains & $2(7.14 \%)$ & $26(92.86 \%)$ & $28(100 \%)$ & $\mathrm{p}<0.001$ \\
\hline Diagnosed diabetes & $23(65.71 \%)$ & $12(34.28 \%)$ & $35(100 \%)$ & $\mathrm{p}>0.05$ \\
\hline Diagnosed cardiac morbidity & $13(52 \%)$ & $12(48 \%)$ & $25(100 \%)$ & $\mathrm{p}>0.05$ \\
\hline Diagnosed tuberculosis & $4(30.77 \%)$ & $9(69.23 \%)$ & $13(100 \%)$ & \\
\hline
\end{tabular}

On clinical examination, pallor was found in $64.16 \%$ of which $54.8 \%$ was in males and $77.67 \%$ females. The compilation of data from medical records and clinical examinations brought forth the following morbidities. The mean number of morbidity conditions was 2.49; where it was 2.66 in males and 2.27 in females. Cataract, joint pain, chronic cough, tuberculosis, and various veins were more prevalent in females and toothache, impaired hearing, HTN, skin diseases, diabetes, and bladder issues were dominant ones among males. They are presented in Figure 1.

The South-East Asian BMI cutoff $\left(23 \mathrm{~kg} / \mathrm{m}^{2}\right)$ was adopted for better accuracy. All morbidities were compared with B.M.I and their associations observed. Joint problems (pain and deformity), chronic cough, 'Bowel and Bladder' complaints, and diabetes were found to have a significant association $(p<0.05)$ with BMI. The detailed analysis is presented in Table 3.

\section{Discussion}

Illiteracy, poor economic condition and deterioration of family support were evident among the studied subjects. N. Bayapa Reddy et al in their Chennai study opined that a majority of the subjects in old age were widows/widowers, illiterates, living with family, and showing economic dependency. ${ }^{8}$ Prabha Adhikari in her special article on unmeet need of Indian geriatrics also highlighted the issue of poverty, lack of income security and poor access to health care as a major determinant of disability and mortality in older persons. ${ }^{9}$
In this study, it was seen that $88.46 \%$ of geriatrics were affected by at least one medical condition. Srinivas K. et al., ${ }^{10}$ Bhatia et al., ${ }^{11}$ Niranjan et al. ${ }^{12}$ found out the similar prevalence of medical problems in the range of $85 \%, 85 \%$, and $82.9 \%$ of elderly Indian people respectively. In terms of mean morbid conditions per participants we fount it to be at 2.49. A J Purity et al. ${ }^{13}$ also reported similar figures ( mean morbidity at 2.77 ) in their study.

We observed pallor in $64.16 \%$ of participants. Prevalence of anaemia in the close range was reported in studies by Kamlesh Joshi et al (66.5\%), and A J Purity et al. (52.5\%). (3,14 $^{13}$ The following proportion of participants in the concluded study reported with cataract $(32.92 \%)$, Joint complaints (34.23\%), and toothache (33.46\%). This observation finds strength from researchers like Kamlesh Joshi et al where proportions of participants with cataract were $38.0 \%$, and osteoarthritis $33.0 \%$, and A J Purity et al who found out joint problems in $43.4 \%$, dental and chewing problems in $42 \%$, reduced visual acuity in $57 \%$ of elderly studied by them. ${ }^{13,14}$

All 9 variables under Functional status assessment (ADL and $I A D L)$ were compared with participants nutritional grades and all of them were found to be strongly associated with it. Participant's deteriorating nutrition had a deleterious effect on the functional status of the elderly $(p<0.001)$. Studies by Yi Chia Huang et al and Maria R M Oliveira et al observed higher prevalence of malnutrition in the functionally dependent group than the non-functionally dependent group (44.7\% v/s 25\%) based on Nutrition Risk Index (NRI). ${ }^{15,16}$ 


\section{Strengths and limitations}

Use of well-validated tools like 'MNA' and 'Geriatric Health Questionnaire' developed by Gerald Jogrest for nutritional and health status assessment were the strong points of the study. Selecting the population $\geq 65$ years was planned to get a realistic picture of old age population.

Health status assessment on the basis of self-reporting and clinical examination, without investigatory supports were our main limitations.

\section{Conclusion}

Though it is difficult to generalize the findings the application of the current methodology on diverse settings could be useful in reflection the true scenario. Old Age is also known as 'Second Childhood.'17 With the changing scenario and demographic transition favouring geriatric population, the Government should have focus activities in the line of the $\mathrm{RCH}$ program. Though we have drafted 'National Programme for Health Care of the Elderly (NPHCE)'a comprehensive package, under Non-Communicable Division with the Validity of the Scheme till 2016-17, the deliverables were grossly unmet. ${ }^{18}$

\section{Acknowledgement}

We are thankful to ICMR for their support under STS platform,REFERENCE NUMBER: 2010-00995. Our heartfelt thanks to all study participants, the local healthcare professionals and interns of the department for rendering their wholehearted support. A special thanks to Miss Bidushi Mishra a $1^{\text {st }}$ BDS student and Miss Gitisha Mishra a student from $12^{\text {th }}$ standard for their inputs in manuscript designing and development. Dr Nidhi D Sinha, Associate professor, Department of dentistry, R D Gardi Medical College deserves a special mention for her critical input.

\section{Conflict of Interest: None}

\section{References}

1. Prakash R, Chodharu SK, Shankar singh U. A Study of Morbidity Pattern among Geriatric Population in An Urban Area of Udaipur Rajasthan. IJCM 2004; 29(1): 1-35.

2. United Nations - World Population Prospects. <a href='https://www.macrotrends.net/countries/IND/ India/life-expectancy'>India Life Expectancy 1950$2020</ a>$. www.macrotrends. net. Retrieved 202004-26.

3. Copyright Census Population 2020 Data. Accessed on 26.04.2020.

4. Barker T C. Health and functional status of elderly in a Polynesian population. J Cross cultural Gerontology 1989; 4: 163-194.

5. Solomons et al. Uses of anthropometry in the elderly in the field setting with notes on screening in developing countries. Asia Pac J Clin Nutr 1993; 2: 15-23.

6. http://www.healthcare.uiowa.edu/igec/tools/function/ geriatric_health_questionnaire.pdf (accessed on26/04/2020).http://www.mna-elderly.com (accessed on- 26/04/2020).

7. Bayapa Reddy N, Pallavi M, Nagarjuna Reddy N, Sainarasimha Reddy C, Singh RK, Pirabu RA. Psychological Morbidity Status Among the Rural Geriatric Population of Tamil Nadu, India: A Cross-sectional Study. Indian J Psychol Med 2012; 34(3): 227-231. DOI: 10.4103/02537176.106016.

8. Adhikari P. Geriatric health care in India - Unmet needs and the way forward. Arch Med Health Sci 2017; 5: 112-114.

9. Srinivasn K et al. Prevalence of health related disability among community dwelling elderly from middle socioeconomic strata in Bangaluru, India. Indian J Med Res 2010; 131: 515-521.

10. Bhatia SPS , Swami HM, Thakur JS, Bhatia V. A study of Health problems and loneliness among the elderly in Chandigarh. Indian J Commun Med 2007; 32: 255-258.

11. Niranjan GV, Vasundhra MK. A study of Health status of aged persons in slums of urban field practice area, Bangalore. Indian J Commun Med 1996; 21(2): 37-40.

12. Purty AJ, Bazroy J, Kar M, Vasudevan K, Veliath A, Panda P. Morbidity pattern among the elderly population in the rural area of Tamil Nadu, India. Turk J Med Sci 36(2006); 45-50.

13. Joshi K, Kumar J, Avasthi A. Morbidity profile and its relationship with disability and psychological distress among elderly people in Northern India. Int J Epi 2003; 32: 978-987. DOI:10.1093/ije/dyg204

14. Anil Jacob Purity. Morbidity pattern among the elderly population in the rural area of Tamil Nadu, India. Turk J Med Sci 36(2006); 45-50.

15. Huang YC, Wueng SL, Ou CC, Cheng $\mathrm{CH}$, Su KH. Nutritional status of functionally dependent and nonfunctionally dependent elderly in Taiwan. J Amer Col Nut 2001; 20(2): 135-142.

16. Oliveira MRM, Fogaça KCP, Leandro-Merhi VA. Nutritional status and functional capacity of hospitalized elderly. Nutr J 2009; 8: 54. DOI 10.1186/1475-28918-54.

17. Covey HC. A Return to Infancy: Old Age and the Second Childhood in History. The International Journal of Aging and Human Development 1993; 36(2): 81-90.

18. https://doi.org/10.2190/3FNY-20EM-7L4Y-5FGM; https://main.mohfw.gov.in/. Accessed on 28.04.2020. 